\title{
An Assessment of Resiliency and Life Satisfaction in High School-Aged Students in Belize
}

\author{
Rachel Youngblom ${ }^{1}$, Daniel Houlihan ${ }^{1} \&$ Julene Nolan $^{1}$ \\ ${ }^{1}$ Department of Psychology, Minnesota State University, Mankato, USA \\ Correspondence: Daniel Houlihan, Department of Psychology, Minnesota State University, Mankato, 56001, \\ USA. Tel: 1-507-389-6308. E-mail: daniel.houlihan@mnsu.edu
}

Received: August 27, 2014

doi:10.5539/ijps.v6n4p115
Accepted: September 12, $2014 \quad$ Online Published: November 18, 2014

URL: http://dx.doi.org/10.5539/ijps.v6n4p115

\begin{abstract}
This study assesses resiliency and life satisfaction of high school youth from Belize. Due to the contrast of geography, culture, and economic characteristics, between Belize and the U.S. many differences were hypothesized to be found. Resiliency and life satisfaction were hypothesized (a) to be lower in the youth from Belize when compared with previous studies of youth conducted in the United States, (b) youth in Belize, who have high resilience, will also have high life satisfaction and (c) youth who has low life satisfaction will also have very little resiliency.
\end{abstract}

Keywords: resiliency, life satisfaction, family involvement, academic achievement, cross-culture, Belize

\section{Introduction}

Research on life factors and situations that affect the academic performance of children from developing countries is beginning to emerge as we find that there are some global consistencies as well as inconsistencies that effect children within their academic settings when compared to students within the United States (Cole \& Brown, 2002; Park, 2005; Punamaki, Qouta, \& Sarraj, 2001). Based on previous research, we know that factors such as resiliency and life satisfaction are all important contributors to school success. However, empirical investigations within the United States, and further, developing countries that assess resiliency and the relationship with life satisfaction are sparse and fail to exist in the international school psychology field. Therefore, in this current study we aim to take a closer look at these factors, how they are addressed currently within the current United States based literature, and ultimately how these factors may affect the academic achievement of youths within the underdeveloped country of Belize.

\subsection{Resiliency}

Resiliency can be described as a "process of, capacity for, or outcome of successful adaptation despite challenging or threatening circumstances" (Masten, Best, \& Garmezy, 1991, p. 426). This description of a "process" gives a broad level of understanding that there are many different facets that may influence the level of resiliency within an individual and that resiliency may change over time. The concept of a "process" points to promising outcomes that when we pinpoint specific factors to increase resiliency we will be armed with interventions to equip students to become more resilient individuals. The pioneer research in resiliency can be traced back to Garmezy (1971) where resistance and growth among poverty-stricken populations was studied. Garmezy observed that although specific adverse environmental conditions were present, a minority of the individuals were not negatively affected. Through continued research in the field of resiliency we are now provided with the knowledge that there are certain risks and protective factors that may hinder or support resiliency in children.

Certain risk factors that may compromise the resiliency of an individual may be the result of one or multiple factors and are a proponent of individual characteristics, family context, and community/social associations. All of these may be considered risk factors if they increase the likelihood that a maladaptive outcome could occur (Murray, 2003). More specific risk factors include individual cognitive deficits, poverty and violence, poor parenting skills, family instability, poor maternal mental health, and low socioeconomic status, all of which have been linked to poor academic achievement and an increase in mental health disabilities (Condly, 2006). 
Conversely, an individual that may possess high resiliency may have a variety of protective factors in place that may come from one or all of three different domains. These domains consist of individual factors (intellectual ability, good health, and positivity); family factors (caring familial relationships, family support, proper parenting); and also community factors (school involvement, church/religious membership, extracurricular activities; Carlton et al., 1999). These individuals with high resiliency maintain a high locus of control, have high self-esteem, are able to solve social problems, and are able to recuperate from adversity (Edwards, Mumford, \& Serra-Roldan, 2007).

An extensive study conducted by Felner et al. (1995) sought to investigate specific at-risk factors of resiliency; one being household disadvantage. The results showed that the children's families who were considered as being from a low socio-economic status (SES) in which parents worked within an unskilled and low-paying position, were found to have low levels of school achievement. However, these effects have found to be mediated by positive experiences within the school environment (Masten et al., 1990). These positive experiences have been shown to lessen the effects from the stressful environment at home (Rutter, 1979). Yet, many of these studies have been confined to a single geographic area and future research is needed to collect data concerning youth and their strength of resiliency from areas of greater diversity and levels of disadvantage (Felner et al.). Expanding the geographical area, broadening the sample range of disadvantage and range of educational contexts may prove to produce stronger and more persistent patterns of relationship with adaptational outcomes.

Resiliency is recognized as an ecological phenomenon shaped by cultural influences and therefore, knowledge and application of resilience is crucial if school psychologists wish to impact students and the cultures they come from (Theron \& Donald, 2012). Due to diverse cultures and contexts, the resiliency building process cannot be assumed to be the same for all children globally. Toland and Carrigan (2011) go even further by strongly urging school psychologists to make resilience theory a core proponent of the function behind their work. In addition, school psychologists must be aware of culturally and geographically specific, local and unique resources in addition to the global consistencies of what we know about resilience.

Rutter (2005) recognizes that the presence of protective factors alone does not guarantee resilience within an individual. However a cultural understanding of resilience allows individuals within that context to be responsible and proactive toward their own resilience. Therefore, individuals will be able to take necessary action to increase resilience that is culture-specific even if those actions may deviate from expectations that other cultures view as the norm (Theron \& Donald, 2012). Through the knowledge of resiliency within a specific context and across a variety of domains, school psychologists will be able to make well-informed prevention and intervention strategies; inform teachers and staff of resiliency building practices; and collaborate within the community to produce resilient youths.

\subsection{Life Satisfaction}

An increasing amount of research has been conducted in the area of life satisfaction (LS) and subjective well-being (SWB) as it pertains to children and youth within the United States, however global research in this area is currently lacking. Life satisfaction is often referred to as an individual's well-being and their own perception of how their life is going and the hope they have for their future (Bailey, Eng, Frisch, \& Snyder, 2007). An individual's global life satisfaction is based upon how they assess different life domains such as their satisfaction with their friends, family, school, self and living environment (Huebner, 1994). Research has also found that LS may be consistent through time from childhood to adolescence (Costa \& McCrae, 1980; Huebner, Laughlin, Ash, \& Gilman, 1998).

An extensive review of the literature on LS was conducted by Proctor, Linley, and Maltby (2009) that reviewed 141 empirical studies. From these studies significant information was gleaned that summarized areas pertaining to youth LS that included, but not limited to: demographics, physical health, relationships, environment, culture, and disability. Proctor et al. also touched on the benefits of high LS and character strengths of those who have LS. Such findings show that socio-economic status is positively related to LS; Caucasians report higher LS than African Americans; poor physical health is related to low LS; poor parental relationships with children indicated low LS and positively perceived parental qualities, parental styles, parental characteristics, and dyadic functioning points to positive LS in adolescents. Further, children that reside in neighborhoods with high problem levels and live in poorly maintained homes reported low LS and familial unhappiness. High LS has also been shown to have a positive relationship with higher GPAs, and a negative relationship with a poor attitude towards school, and poor attitude towards teachers (Gilman \& Huebner, 2006).

Some of the current literature suggests that high LS is often related to academic achievement and that individuals with high LS are also found to be more resilient when life becomes stressful (Proctor et al., 2009). However, the 
little research that has been conducted on youth LS indicates that this may not be a cross cultural phenomenon and different life domains may influence overall LS throughout the world depending on the geographical area and cultures which are assessed. For example, in collectivistic cultures, high LS denotes adhering to social norms; whereas in individualistic cultures, such as the U.S., high LS points to engaging in anything that makes the individual happy (Suh, Diener, Oishi, \& Triandis, 1998). A study also done by Park and Huebner (2005) found significant differences between students from Korea and students in America when assessing LS within the domains of Self and School. On the Self domain, Korean students reported significantly less satisfaction and on the School domain, American students reported significantly less satisfaction.

Although cross-cultural research has been conducted predominately assessing industrialized countries (Diener \& Diener, 1996) very few studies have yet been completed that assess LS in developing countries, especially as it relates to the youth of that country and the role it plays on their academic achievement. A full understanding of culture-specific LS is imperative in order to successfully promote and aid the achievement of students within those cultures. Proctor et al. (2009) stress that evaluation of LS is needed in order to inform us of the multifaceted effects and impacts that determine the well-being of our youth and calculate changes that must be made within our educational programs in order to boost the intensity and continuation of LS. Without the knowledge of culture-specific values and beliefs, educators' efforts may become futile if globally-perceived characteristics of LS and SWB do not coincide with the students'.

The aim of this current study is to assess a variety of variables that have been shown through previous research to hinder high academic achievement. Such variables that will be assessed are related to resiliency and life satisfaction. Belize was chosen for this study due to its status as a developing country, diverse society, and convenience in that English is its official language. A developing country is considered a nation that has a low standard of living, has a nonexistent industrial base and fails to be competitive in the global economy in relation to its Human Development Index (HDI; Sullivan \& Sheffrin, 2003). The HDI is, "a composite index measuring average achievement in three basic dimensions of human development - a long and healthy life, knowledge and a decent standard of living" (UNDP, 2011a p. 130). As of 2011, Belize was placed $93^{\text {rd }}$ out of 187 countries on the HDI (UNDP, 2011a) whereas the United States was placed at number four. Other comparisons between the two countries can be seen in Table 1. Due to economic hardships in previous years, Belize has had to cut funding for social programs that has been detrimental to the health and education systems and further rely heavily on exportation of agriculture and tourism to support the country (Crooks, 1997).

Table 1. Comparisons between the country of Belize and the United States as of 2011

\begin{tabular}{lll}
\hline Measure & Belize & United States \\
\hline Position on the HDI & 93 & 4 \\
Mean Years of Schooling & 8.0 & 12.4 \\
Expected Years of Schooling & 12.4 & 16.0 \\
Gross National Income per Capita (GNI; in dollars) & 5,812 & 43,017 \\
Percent of Population Below the Poverty Line & 43.0 & 15.1 \\
Homicide Rate per/100,000 Individuals (as of 2008) & 34.3 & 5.2 \\
\hline
\end{tabular}

Note. All information given was compiled from the UNdata and UNDP sources cited in the reference section.

Given the less than ideal conditions (i.e., high poverty rate, high crime rate, low level of education, poor health care) of youths in Belize we hypothesize that (a) resiliency and life satisfaction will be low when compared with that of the youths in the United States, (b) youth in Belize, who have high resilience will also have high life satisfaction and (c) students who have low life satisfaction, will also have low resiliency. Results that conflict with the stated hypothesis will be carefully explored to learn more about cultural variables that make resiliency and life satisfaction unique within the specific geographical area; and the impact that these differences may have on student academic achievement. 


\section{Method}

\subsection{Participants}

High school students $(\mathrm{N}=93$; ages 15-18) from Belize, Central America participated in this study. Student participants were currently enrolled within one of the high schools in Belize where data was collected. The data was collected in 4 different classrooms; each classroom represented a specific grade within the school. A Preparatory (Prep) classroom contained 14 participants and was described as a pre-entry grade prior to the Freshman grade level. These were students who had completed $8^{\text {th }}$ grade, however, had not yet passed entrance exams to be fully admitted to the Freshman class of the high school. The fully admitted Freshman class contained 30 participants; the Sophomore class contained 30 participants; and the Junior class contained 19 participants. The high school was contacted and verbal permission was received from the school in order to allow their students to take part in a research study. Once school permission and consent was achieved, individual teachers were contacted regarding allowing the students within their classrooms to participate. The high school counselor also played an active role in data collection and served as a mediator witnin the high school environment.

\section{Measures}

\subsection{Measures of Resilience}

The Resiliency Scales for Children and Adolescents-A Profile of Personal Strength (RSCA) (Prince-Embury, 2005) was employed to measure areas of strength and/or vulnerability related to psychological resilience. This measure consists of three different scales, all that have 20-24 questions each, for a total of 64 items. All responses are given on a 5-point Likert scale (0-Never, 1-Rarely, 2-Sometimes, 3-Often, 4-Almost Always) that assesses Sense of Mastery, Sense of Relatedness, and Emotional Reactivity. The Sense of Mastery Scale measures optimism, self-efficacy, and adaptability; the Sense of Relatedness Scale measures trust, support, comfort and tolerance; and the Emotional Reactivity Scale measures sensitivity, recovery and impairment. Chronbach's alpha coefficients indicate good internal consistency ranging from .93 to .95 for the total sample (males and females) and the standard error of measurement indicates good reliability ranging from .90 to 2.45 for the total sample on all subscales (FRIENDS, 2005).

\subsection{Measures of Life Satisfaction}

The Multidimensional Life Satisfaction Survey (MLSS) (Hubener, 2001) was used to provide a profile of the child's satisfaction with school, family, and friends as well as to assess general overall life satisfaction. The survey is comprised of 40 items that inquire across the domains of 5 different areas; Family, Friends, School, Living Environment, and Self. Sample questions given consisted of: "My family is better than most; My friends are nice to me; I feel bad at school; I wished I lived in a different house; I think I am good looking". All responses are given on a 6-point Likert scale (1-Strongly Disagree, 2-Moderately Disagree, 3-Mildly Disagree, 4-Mildly Agree, 5-Moderately Agree, 6-Strongly Agree). Internal consistency using Chronbach's alpha coefficient suggest that the scales are acceptable for research purposes and that reliabilities range from .70 s to low .90s (Huebner). Other self-report well-being measures have been used to show convergent and discriminant validity with the MLSS and have demonstrated predicted correlations (Huebner, 1994; Huebner et al., 1998).

\section{Procedure}

Once classrooms within the targeted school were identified, the school counselor was contacted by the researchers and asked to be involved in the data collection. The school counselor facilitated the interaction between the researchers, teachers, and students by bringing the researchers to the classrooms and asking the students to help the researchers with a project they were conducting in the United States. All students in the classroom then had the option to complete the Life Satisfaction and Resiliency Scales questionnaires if they so choose.

The students that chose to participate in the study received a randomized packet starting either with the Life Satisfaction or Resiliency Scales. The questionnaire packets were counterbalanced so that students would not be able to discuss comparable answers with their peers. Data was collected immediately after and held by the researcher.

\section{Results}

All variables were examined for normality of distribution regarding skew and kurtosis. Of these variables, only one (Self) in the Life Satisfaction Survey yielded a statistic that exceeded an absolute value of 1 with a skew 
statistic of -1.57 and a kurtosis statistic of 3.36. Data were not transformed. No multivariate outliers were identified and all 92 cases were included in analysis using SPSS.

\subsection{Resilience and Life Satisfaction}

A bivariate correlational analysis was conducted to determine the relationship between the overall life satisfaction and emotional reactivity, sense of mastery, sense of relatedness, resources, and vulnerability. An intercorrelation between predictors was also conducted and results are presented in Table 2 .

Table 2. Outcome and predictor variables intercorrelations ( $\mathrm{N}=93)$

\begin{tabular}{|c|c|c|c|c|c|c|c|}
\hline Variable & $\mathrm{M}(\mathrm{SD})$ & 1 & 2 & 3 & 4 & 5 & 6 \\
\hline Overall Life Satisfaction & & 1 & & & & & \\
\hline Emotional Reactivity & & $-.26^{*}$ & 1 & & & & \\
\hline Sense of Mastery & & $.43^{* *}$ & -.18 & 1 & & & \\
\hline Sense of Relatedness & & $.56^{* *}$ & $-.23 *$ & $.87 * *$ & 1 & & \\
\hline Resources & & $.50 * *$ & $-83 * *$ & $-.67 * *$ & $-.65^{* *}$ & 1 & \\
\hline Vulnerability & & $.58^{* *}$ & $-.28 * *$ & $.37 * *$ & $.26^{*}$ & $.35 * *$ & 1 \\
\hline
\end{tabular}

$p<.05^{*}, p<.01^{* *}$

A stepwise multiple regression analysis was conducted to determine which of the resilience factors contributed to overall life satisfaction for the entire group of students $(\mathrm{N}=92)$. Results indicated that only Resources was a significant predictor of Overall Life Satisfaction, and it explained 33\% of the variance $F(2,92)=22.54 p<.001$ Beta $=.528$

One-way ANOVA was used to determine differences in Life Satisfaction scores according to group membership. No significant differences were identified overall, however significant group differences were identified with regard to Emotional Reactivity on the Resilience scale, such that the Prep class $(M=62.64, S D=8.71, p<.05)$ was significantly higher than the Junior class $(M=51.58, S D=11.21, p<.05)$.

Finally, stepwise multiple regression analyses were conducted by class to determine which factor of Resilience contributed to Overall Life Satisfaction by grade. Similarly to the overall findings, Resources was the only significant predictor of Overall Life Satisfaction for the Prep students and explained $49 \%$ of the variance $F(1,13)=11.33 p<.01$ Beta $=.70$. Resources was also the best predictor for the Freshmen class and explained $43 \%$ of the variance $F(4,29)=4.70 p<.01$.

Results for the Sophomore class were slightly different and the stepwise multiple regression revealed that Sense of Mastery and Resources were both significant predictors of Overall Life Satisfaction, and this model explained $62 \%$ of the variance $F(2,29)=21.67 p<.001$. Finally, for Juniors, Sense of Relatedness was the only significant predictor of Overall Life Satisfaction and the model explained $42 \%$ of the variance $F(1,18)=12.33 p<.01$. Summary of predictors for all significant models and their Beta weights are presented by class in Table 3 .

Table 3. Beta weights for all predictors in significant models

\begin{tabular}{llllll}
\hline & All Grades & Prep & Freshmen & Sophomore & Junior \\
Variable & $\beta$ & $\beta$ & $\beta$ & $\beta$ & $\beta$ \\
\hline Emotional Reactivity & - & - & - & - & - \\
Sense of Mastery & - & - & 4.76 & -.80 & - \\
Sense of Relatedness & - & - & -4.95 & - & .65 \\
Resources & .53 & .70 & 8.74 & 1.37 & - \\
Vulnerability & - & - & -.72 & - & - \\
\hline
\end{tabular}




\section{Discussion}

Although this is only one sample of students from one high school in Belize, it should be noted that there are not many high schools throughout the country, as it is not mandatory for students to continue their education past $8^{\text {th }}$ grade; referred to as Standard VI in Belize. Therefore, this may not be a complete representation of all students who attend high school in Belize. Further, attending high school is considered a privilege, in that the families must pay for their student to attend a high school and receive an education beyond the mandatory $8^{\text {th }}$ grade (i.e. Standard VI). Therefore, individuals that are the same age, however lack the means to attend high school, may be an additional population with different views of resiliency and life satisfaction.

Future research should be expanded to include, not only students who are attending a high school, but additionally include students who may be considered within the age range of adolescent and young adult. Targeting this age range may give us better insight as to how the country and their communities may support these young adults as they transition into becoming upstanding citizens who positively impact and contribute to their community.

\section{Conclusion}

The overarching outcome and conclusion is that resources are of prominent concern among Belizean youth and directly correlate with a sense of life satisfaction and the ability to approach difficult life situations. As the youth progressed through secondary school, and in age, it was noted that a sense of mastery became of more concern as joining the work force neared and became a focal point. It is apparent that a perceived lack of opportunity is the most significant challenge facing the youth of Belize.

\section{References}

Bailey, T. C., Eng, W., Frisch, M. B., \& Snyder, C. R. (2007). Hope and optimism as related to life satisfaction. The Journal of Positive Psychology, 2, 168-175. http://dx.doi.org/10.1080/17439760701409546

Carlton, B. S., Goebert, D. A., Miyamoto, R. H., Andrade, N. N., Hishinuma, E. S., Makini, G. K., Jr., Yuen, N. Y. C., ... Nishimura, S. T. (1999). Resilience, family adversity, and well-being among Hawaiian and non-Hawaiian adolescents. International Journal of Social Psychiatry, 52(4), 291-308. http://dx.doi.org/10.1177/0020764006065136

Cole, E., \& Brown, R. S. (2002). Psychological needs of post-war children in Kosovo: A preliminary analysis. School Psychology International, 23, 131-147. http://dx.doi.org/10.1177/0143034302023002912

Condly, S. J. (2006). Resilience in children: A review of literature with implications for education. Urban Education, 41, 211-236. http://dx.doi.org/10.1177/0042085906287902

Costa, P. T. Jr., \& McCrae, R. R. (1980). Still stable after all these years: Personality as a key to some issues in adulthood and old age. In P. B. Baltes, \& O. G. Brim, Jr. (Eds.), Life span development and behavior (Vol. 3, pp. 65-102). New York: Academic Press.

Crooks, D. L. (1997). Biocultural factors in school achievement for Mopan children in Belize. American Anthropologist, 99(3), 586-601. http://dx.doi.org/10.1525/aa.1997.99.3.586

Diener, E., \& Diener, C. (1996). Most people are happy. Psychological Science, 7, 181-185. http://dx.doi.org/10.1111/j.1467-9280.1996.tb00354.x

Edwards, O. W., Mumford, V. E., \& Serra-Roldan, R. (2007). A positive youth development model for students $\begin{array}{lllll}\text { considered at-risk. School Psychology } & \text { International, } & 28,45 .\end{array}$ http://dx.doi.org/10.1177/0143034307075673

Felner, R. D., Brand, S., DuBois, D. L., Adan, A. M., Mulhall, P. R., \& Evans, E. G. (1995). Socioeconomic disadvantaged, proximal environmental experience, and socioemotional and academic adjustment in early adolescence: Investigation of a mediated effects model. Child Development, 66, 774-792. http://dx.doi.org/10.2307/1131950

Garmezy, N. (1971). Vulnerability research and the issue of primary prevention. American Journal of Orthopsychiatry, 41, 101-116. http://dx.doi.org/10.1111/j.1939-0025.1971.tb01111.x

Gilman, R., \& Huebner, E. S. (2006). Characteristics of adolescents who report very high life satisfaction. Journal of Youth and Adolescence, 35, 311-319. http://dx.doi.org/10.1007/s10964-006-9036-7

Huebner, E. S. (1994). Preliminary development and validation of a multidimensional life satisfaction scale for children. Journal of Psychological Assessment, 6, 149-158. http://dx.doi.org/10.1037/1040-3590.6.2.149 
Huebner, E. S. (2001). Manual for the multidimensional students' life satisfaction scale. Colombia, SC: University of South Carolina Department of Psychology. Retrieved from http://www.cas.sc.edu/PSYC/pdfdocs/huebslssmanual.pdf

Huebner, E. S., Laughlin, J. E., Ash, C., \& Gilman, R. (1998). Further validation of the multidimensional students' life satisfaction scale. Journal of Psychological Assessment, 16, 118-134. http://dx.doi.org/10.1177/073428299801600202

Masten, A. S., Best, K. M., \& Garmezy, N. (1990). Resilience and development: Contributions from the study of children who overcome adversity. Development and Psychopathology, 2, 425-444. http://dx.doi.org/10.1017/S0954579400005812

Murray, C. (2003). Risk factors, protective factors, vulnerability, and resilience: A framework for understanding the adult transitions of youth with high-incidence disabilities. Remedial and Special Education, 24, 16-26. http://dx.doi.org/10.1177/074193250302400102

Park, N. (2005). Life satisfaction among Korean children and youth: A developmental perspective. School Psychology International, 26, 209-223. http://dx.doi.org/10.1177/0143034305052914

Park, N., \& Huebner, E. S. (2005). A cross-cultural study of the levels and correlates of life satisfaction among $\begin{array}{lllll}\text { adolescents. Journal of Cross-Cultural Psychology, 36(4), 444-456. } & \text {. }\end{array}$ http://dx.doi.org/10.1177/0022022105275961

Prince-Embury, S. (2005). Resiliency Scale for Adolescents: A Profile of Personal Strengths. San Antonio, TX: Harcourt Assessments Inc.

Proctor, C. L., Linley, P. A., \& Maltby, J. (2009). Youth life satisfaction: A review of the literature. Journal of Happiness Studies, 10, 583-630. http://dx.doi.org/10.1007/s10902-008-9110-9

Punamaki, R. L., Qouta, S., \& El-Sarraj, E. (2001). Resiliency factors predicting psychological adjustment after political violence among Palestinian children. International Journal of Behavioral Development, 25, 256-267. http://dx.doi.org/10.1080/01650250042000294

Rutter, M. (1979). Maternal deprivation, 1972-1978: New findings, new concepts, new approaches. Child Development, 50, 283-305. http://dx.doi.org/10.2307/1129404

Rutter, M. (2005). Environmentally mediated risks for psychopathology: Research strategies and findings. Journal of American Academy of Child and Adolescent Psychiatry, 44, 3-18. http://dx.doi.org/10.1097/01.chi.0000145374.45992.c9

Suh, E., Diener, E., Oishi, S., \& Triandis, H. C. (1998). The shifting basis of life satisfaction judgments across cultures: Emotions versus norms. Journal of Personality and Social Psychology, 74, 482-493. http://dx.doi.org/10.1037/0022-3514.74.2.482

Sullivan, A., \& Sheffrin, S. M. (2003). Economics: Principles in Action. Upper Saddle River, New Jersey: Pearson Prentice Hall.

Theron, L. C., \& Donald, D. R. (2012). Educational psychology and resilience in developing contexts: A rejoinder to Toland and Carrigan (2011). School Psychology International.

Toland, J., \& Carrigan, D. (2011). Educational psychology and resilience: New concept, new opportunities. School Psychology International, 32, 95-106. http://dx.doi.org/10.1177/0143034310397284

United Nations Data Retrieval System (UNdata). (2011). Retrieved from http://data.un.org/Data.aspx?d=UNODC\&f=tableCode\%3a1

United Nations Development Programme (UNDP). (2011a). Human Development Report. New York, NY: Pelgrave MacMillan. Retrieved from http://hdr.undp.org/en/reports/global/hdr2011/

United Nations Development Programme (UNDP). (2011b). Human Development Report: Explanatory note on 2011 HDR composite indices for Belize. Retrieved from http://hdrstats.undp.org/images/explanations/BLZ.pdf 


\section{Copyrights}

Copyright for this article is retained by the author(s), with first publication rights granted to the journal.

This is an open-access article distributed under the terms and conditions of the Creative Commons Attribution license (http://creativecommons.org/licenses/by/3.0/). 